\title{
Geophysical researches for identification of hidden faults in the western region of Banesh, Fars, Iran
}

Raheleh Farhang and Abdolmajid Asadi

* Corresponding author: Abdolmajid Asadi

E-mail: abdolmajidasadi07@gmail.com

\begin{abstract}
Possessing seismic information on active faults is required for earthquake risk estimation. In earthquake prone areas such as Zagros Mountains in which active basement faults are covered by Phanerozoic sedimentary cover, we can use geophysical data such as special resistivity and employ Schlumberger array as an inexpensive and quick method to identify blind faults with high accuracy. For this purpose, 30 vertical electric soundings and 10 profiles were implemented on Banesh Plain in Fars Province of Iran. Using data from geoelectric sections combined with qualitative data, we determined blind faults and sub fractures. The results show two faults zones along east-southwest and northwest-southeast lines and some sub faults and fractures along the Zagros flow.

Keywords: Geophysics. Special Resistivity. Geoelectrics. Schlumberger array. Blind Faults. Banesh. Fars. Iran.
\end{abstract}

\section{INTRODUCTION}

Using geophysical methods in identification of some of ground's physical features such as electric, elastic and magnetic characteristics of rocks and minerals, earth gravity and such characteristics are of great importance. Using geophysical methods, we can extract information from buried geological structures that can be used directly or indirectly in geological studies (Knisel, 2006), discovering minerals, hydrocarbons and underground waters, civil engineering studies (Sudha et al. 2009), environmental studies (Crellier et al. 2007) and etc.

The basis of electric methods in geophysical explorations is measuring electric features of rocks. This method is widely used for identification of geological layers which have different electric features with their surrounding rocks and also for identi- fication of inconsistency levels such as faults and etc. Electric exploration methods are very diverse compared to other geophysical methods. These methods are based on manifestation of superficial impacts which are created due to passing of electric current from the earth. Using these methods, we can measure the electric or electromagnetic potentials, currents and fields created naturally or artificially in the ground. Electrical conduction changes of rocks and minerals are one of the features that makes the usage of this method possible.

In geoelectric method, the induced electric current is directed to the ground by electrodes and then the potential difference between various points is calculated. Measuring the potential difference between different points lead to identification of petrophysical characteristics and deter- 
mination of anisotropy in different directions. This method is best in distinguishing underground layers in terms of their special resistivity and thickness and because of flexibility, high speed, light and portable equipment, low costs of field operations, being economical and ability to directly and qualitatively interpret data, it is one of the strongest discovery methods (Ako and Olorunfemi, 1989)

A geoelectric operation is carried out by two methods: Vertical electric sounding and Horizontal profiling (Kalagari, 2010).

In geoelectric soundings, deep changes of special resistivity and existing layers are investigated using formations in which the distance between some or all electrodes increase symmetrically. A geoelectric interpretation via sounding is done using a specific electrode formation on the ground in a way that the formation's length continually increases after each measurement, whereas the center of formation is fixed on one point on the ground. Thus for each formation length of a superficial special resistivity, we can determine the thickness and special resistivity of underground layers on that point (sounding point or the center of electrode formation). Considering the distance, values of special resistivity are drawn on algorithmic diagrams (both logarithmic axes). Although, methods have been suggested for interpretation of layers' slope, geoelectric sounding only works well when the intersection of layers is horizontal. (Milson, 1989)

Evaluation of a sounding curve might have a few equivalent answers. The duty of geophysics experts is to select a result that best matches the known geological and hydrological buildings of the area. Another selective item is comparison with adjacent soundings. Connecting the signs of a layer in a measured depth by a sounding to deep signs of the next sounding should be made possible in a way that results in a geologically logical and accurate section.

In the profiling method, side changes of special resistivity of underground materials are reviewed along one line of profile. Geoelectric interpretation by profiling using specific electrode formation along one line of profile is in this way: distances between electrodes or formation length (which is either the exploration depth or effective depth that is experimentally appropriate) are kept the same in all the measurement and after each measurement, all the electrodes with the same specific electrode formation and fixed formation length are transferred on the profile line, so that eventually all the profile line gets acquired.

Reviewing side changes of special resistivity resulting from geoelectric measurements via profiling method, we can determine underground irregularities and their range or extent underground. Also, investigating deep or vertical changes of special resistivity resulting from measurements by sounding method can be practically used in hydrological studies and underground waters. 
Figure 1: Schlumberger array

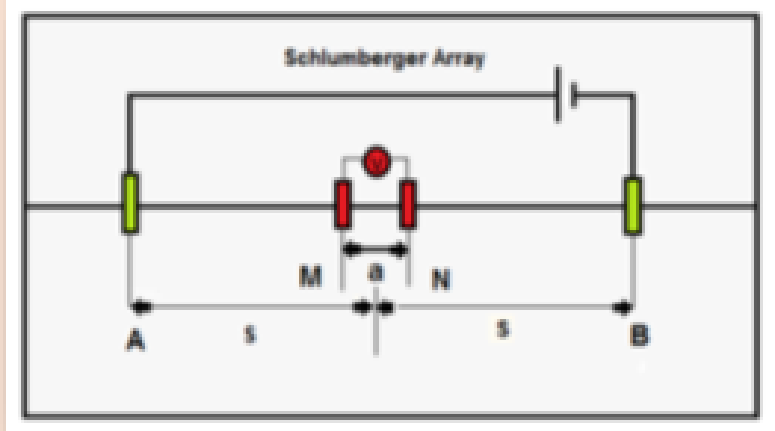

Special Resistivity is calculated by the following equation:

$$
\rho_{a}=\pi \frac{\Delta V}{I}\left[\frac{\left(\frac{A B}{2}\right)^{2}-\left(\frac{M N}{2}\right)^{2}}{M N}\right]
$$

One of the advantages of Schlumberger formation is that $M \& N$ potential electrodes, at least for several length of the current line or distance between A \& B currents, are fixed and do not move. This leads to a significant saving in time and also cable and other equipment consumption. By measuring special resistivity values for $\mathrm{MN}$ (distance between potential electrodes), we can figure out the superficial and side changes of the area under study and distinguish them from deep changes of special resistivity.

In order to determine the geological structures, blind faults and fractures in the area under study, geoelectric sections are investigated using the geoelectric method. The actual special resistivity of the layers and also the geological evidence of the area can help relating separated layers to each other. Geoelectric sections were obtained after analyzing the sounding curves of each profile and by considering interpreted resis- tivity values, the changing procedure of electric resistivity in depth, topographical changes in profile's length based on Schlumberger array and also field information.

\section{GEOGRAPHICAL LOCATION AND ACCESS ROUTES TO THE UNDER-STUDY AREA}

The area under study is located in Fars province and in northwest of Shiraz and is one of the villages in Beyza District. Beyza District is a relatively large plain which is surrounded by mountains from north, south and west; and it is connected toMarvdasht Plain from the east.

Figure 2: Geographical location of Banesh and access routes

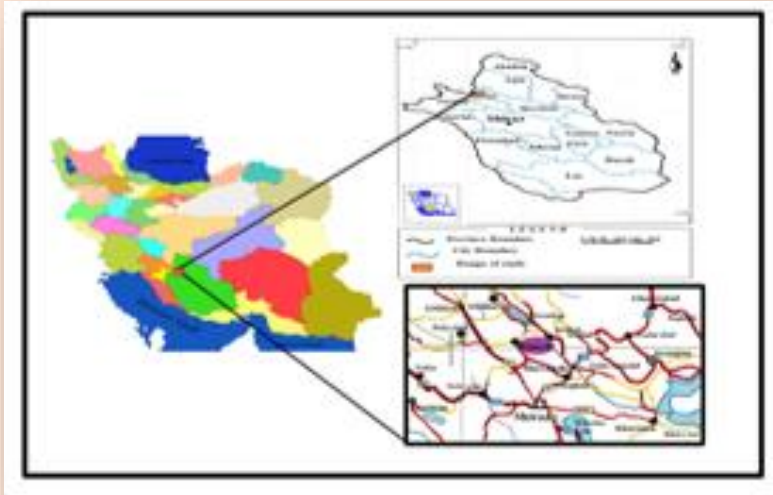

Area's Geology and Tectonics

The area under study, according to Iran's tectonic divisions (Berberian, 1976) is located on the tectonic unit of active folded belt of Zagros. Folded belt, thruster of Zagros as the biggest structural area in Iran, has been formed due to the collision of Arabian plate and Iran's Plateau in late Tertiary (Stocklin, 1968) in the form of mountain range with the approximate length of 1800 Kilometers (Hessami et al., 2001) and one the quiet 
platform of the Arabian continent. Tectonic units in Iran are influenced by the formation and movement of Arabian plate in the south and Eurasia in the north and this has resulted in different procedures in various parts (Aghanabati, 2004). Convergence between continental plates often lead to formation of fold-thrust belts. Land shapes in Zagros are fundamentally structural. The top Phanerozoic sedimentary cover of Zagros is transformed during Neogene orogeny. This transformation is manifested in the form of stretched and wide folds and thrusts; in a way that their axial surface towards north and northeast is sloped (Berberian, 1995). According to geological divisions, the area under study is located in folded Zagros zone and is surrounded by SangPahn Mountains and AliYaghi Mountain in the north, MalAmir Mountain in northeast, Sangpahn Mountain in the northwest and Takhte Sang Olya in south and southeast. The area's exposures include Sarook, Gourpi, Fahliyan, Gadvan, Darian and Kajdomi structures. Along with mentioned structures, Conglomerate of present time, alluvium and recent quaternary sediments possess a wide area. Considering the quaternary sedimentary cover, fractures and gaps have remained hidden in many effect points of the fault. In the heights if this region, anticlines and main faults are seen. Faults are located in mountain borders or the subsiding plain. Strike slip faults have led to deviations along the mountains and topographical views. Studies demonstrate that the area under study in Beyza plain is a result of gravitational tectonic procedures. In this area, a tensile phase has followed the Pasadenian orogeny and a heavy alluvium has occurred which has resulted in numerous folds in the plain being covered by 50 to 300 meters of quaternary sediments. Geophysical data and aerial magnetic maps are consistent with this subject (Shahsavari, 2003).

Figure 3: Location of Banesh and Sounding stations in satellite images (Google Earth)

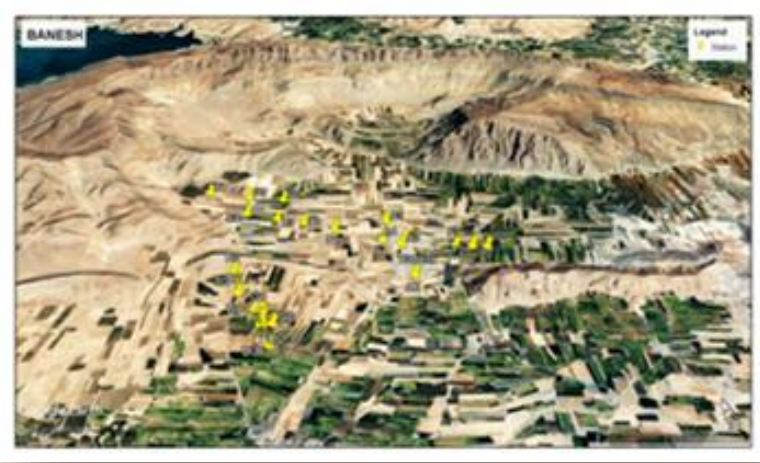

\section{DISCUSSION}

The first step in designing a geophysical interpretation is collecting information related to history of studies and all the available geophysical data related to the desired goal. For this purpose first we visited the area and reviewed 1:100000 and 1:25000 geological maps of Beyza, topographic maps and aerial and satellite images to obtain geological and tectonic generalities for the area under study. After adjusting the existing data and the obtained data in the additional stage, a careful identification of structures and evidence related to faults and area's tectonics was carried out. In the final stage, we use the geoelectric method with Schlumberger array in order to confirm tectonic and geological evidence based on the existence proofs of blind faults in the area. For this purpose, field acquisitions were carried out by the geoelectric device; field acquisitions which consisted of measuring 
and locating the profile of soundings in determined sites (30 vertical soundings in the area) and reading the impedance of tectonic layers ( 10 profiles based on acquired data). Then we analyzed the data and the results were interpreted (Figure 3 ). In the end, geophysical studies and tectonic and geological evidence helped us identify blind faults and fractures of Banesh Plain. In the following, we review some of the stations, profiles, sections and pseudosections.

\section{ANALYZING THE IMPEDANCE CURVE}

Analysis of the impedance curve of $A 1$ stations shows that impedance changes in this stage has a decreasing process until the semi-deep section and then shows increasing process in deep parts. It seems that above-mentioned changes are due to structure change and also due to the passing of the crushed zone from the vicinity of the station. Coarse-grained to medium-grained alluvium in shallow and semi-deep parts are recognizable in this diagram (Figure a-4). By analyzing the impedance curve of $\mathrm{B} 3$ and $\mathrm{C} 2$ stations, it was determined that impedance changes of these stations are increasing from the surface to the depth and at least three main layers can be observed in these stations. Huge resistivity changes are not much seen in these stations and in other words, the gradual increase of resistivity indicates that the crushed zone didn't pass the mentioned stations. In deep parts of B3 station, the calcic floor rock and in C2 station, alluvium part and the rocky layer are well detectable (Figure 4-a \& b). Analyzing the impedance curve of DK2 stations shows that resistivity changes in this station first increase from the surface to the depth and then decreases. The minimum number of layers in this station is three and studies revealed that the floor rock is marlstone which starts at 60 meter depth (Figure 4-d).

Figure 4: an example of impedance curves from each profile

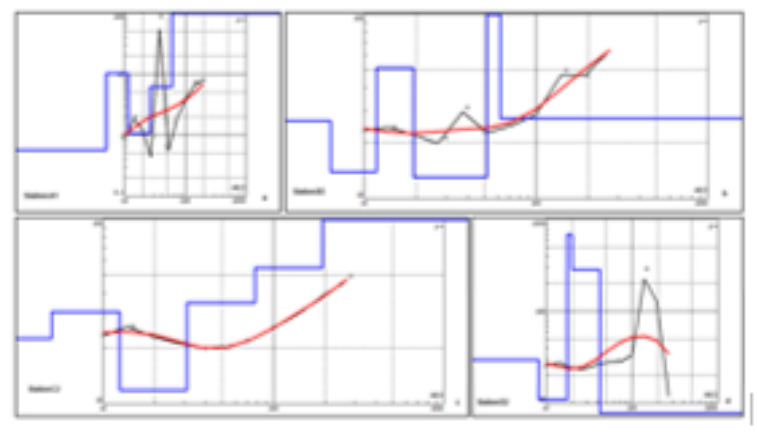

Investigating geoelectric pseudosection curves shows the electrical impedance distribution in a deep section along one profile. In order to provide pseudosections, after smoothing and before interpreting field sounding curves, we draw the values of electrical impedance for soundings of each profile against half the length of current electrodes $(A B / 2)$ (Meshinchi et al., 2013).

Analyzing pseudosection and section of stations of Profile 4 shows that G2, G3 and G4 stations are made from limestone. Resistivity increase especially in GK2 and GK3 stations confirm the above opinion; but this increase is minute, especially in all three GK2, GK3 and GK3 stations and has occurred with a slight slope. The reason for this is the passing of the crushed zone and fault from all these stations. In other words, despite limestone floor, passing of the crushed zone from all three stations has led to moisture penetration in deep parts and consequently led to a significant reduction 
of resistivity increase intensity, especially in real sections. Thus, we can consider that the crushed zone passes all the 3 stations. In Figure 5, location of sounding stations of Profile 4 on Google Earth and geoelectric pseudosections and sections of Profile 4 are depicted.

Figure 5. Location of sounding stations of Profile 4 on Google Earth geoelectric pseudosections and sections of Profile 4

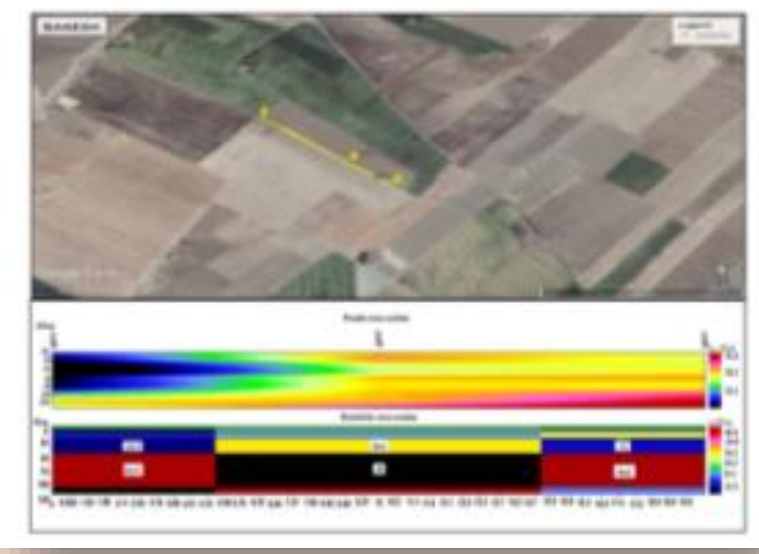

\section{GEOELECTRIC SECTIONS}

After interpreting sounding curves and determining the depth and actual electrical resistivity of subsurface layers in each profile, we can draw the geoelectric section of that profile. The geoelectric section is a vertical slice of subsurface geoelectric layers whose horizontal axis is soundings horizontal distances to one another and the vertical axis is the depth of the layers; and layers are distinguished from each other based on actual special resistivity. Figure 6 shows the geoelectric section of Profile 2 resulting from soundings of D3-G3-G1-B2-B3 as an example.
Figure 6: a) geoelectric sections of Profile 2 on Google Earth and b) geoelectric sections and pseudosections of Profile 2

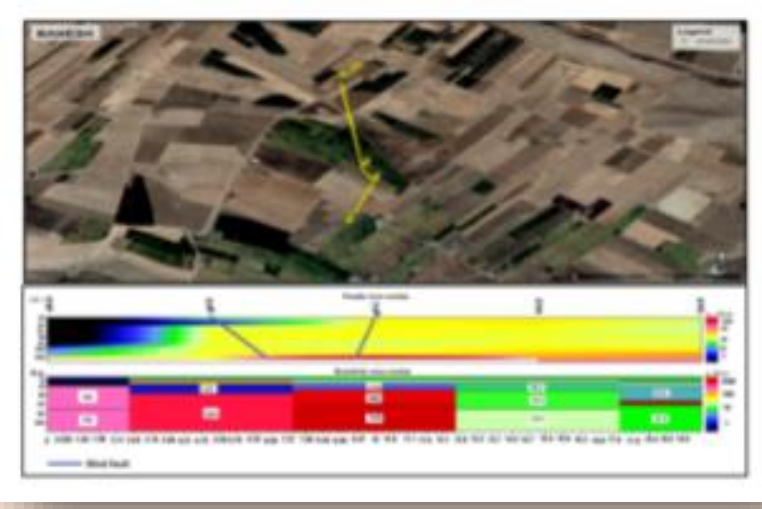

Investigating the pseudosection and section of Profile 2 stations show that in of D3G3-G1-B2 stations, the limestone floor is well detectable. Also in B3 station, the limestone floor with lower resistivity is observable. Whereas, in G3 station, the resistivity significantly decreases compared to the adjacent station, despite the existence of a limestone floor. In addition, in the drawn pseudosection, the passing of the fault and crushedzone along with movement in G3 stations can be observed. It seems that the effect of the crushed zone on G3 station is to an extent that results in moisture penetration from superficial to deep parts and thus provides the preparations for resistivity reduction in the mentioned station compared to adjacent stations.

\section{A GENERAL SAMPLE OF SECTION AND PSEUDOSECTION FROM PROFILE 6 RESULT- ING FROM C1-C3-C2-A5-F3-F2-F1 SOUND- INGS}

Analysis of section and pseudosection of Profile 6 stations show that in A5 and F3 stations sites, because the fault zone is well observable despite limestone floor rock in 
adjacent stations (especially F1 \& F2), the resistivity increment is less intense. Therefore, despite limestone floor, the resistivity changes don't show any significant increase. Also, it seems that $\mathrm{C} 1, \mathrm{C} 3$ and $\mathrm{C} 4$ stationsdue to the distance from A5 station, has a sub fracture which passes along these three stations. Resistivity changes are because of formation change and the crushed zone does not face a sharp increase in resistivity. Especially in the pseudosection, the existence of fault in $\mathrm{A} 5$ and $\mathrm{F} 3$ stations are well detectable.

Figure 7: a) Geoelectrical sections of Profile 6 on Google Earth b) Geoelectric pseudosections and sections of Profile 6 and c) Impedance diagram of Profile 6

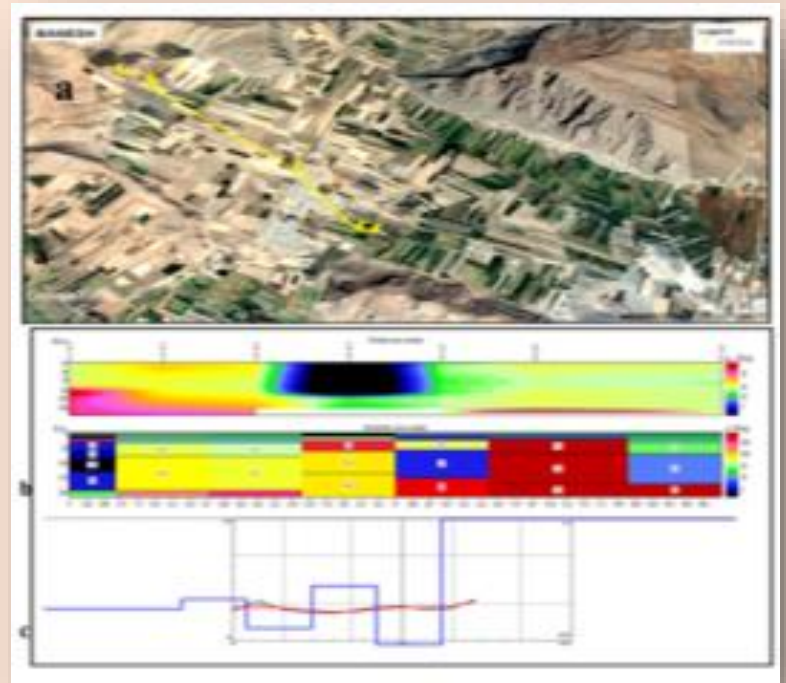

\section{CONCLUSION}

Banesh village in Beyza District, situated on northwest of Shiraz is located on active fold belt tectonic unit of Zagros which is covered by sediments related to Phanerozoic era and has hidden many of geological structures including faults. According to this, we used a geoelectric method to iden- tify the area's structures; a method that is based on Schlumberger array which is an appropriate method with high reliability in identification of hidden structures. Paying attention to geoelectric data and their comparison with field and morphotectonic acquisitions in the area shows active plain and blind faults in the region under study. Based on this and in order to identify the possible location of faults, 30 soundings were provided in the area and 10 profiles were selected. The results from sounding sections and pseudosections and profiles show that the area under study is a foldfaulting area. Especially, the precise location of thrust faults in the plain floor which was not known because of covering by quaternary alluvial deposits, is now determined with this method. Studies show that the rock floor is limestone, but in some areas, marlstone has also been seen. Also, studies have well shown that resistive reduction is seen in stations which faulting zone has passed or in stations near crushed zone, despite limestone floor. Therefore, because of the crushed zone, moisture can easily penetrate from surface to the depth. Also, studies show the faulting zone passing from A1 to A5 stations and is responsible for underground water conduction in the region. In the follow-up, it was determined that G1 to $\mathrm{G} 4$ stations are on the fault. The general results show that two faulting zones are along the northeast-southwest and northwest-southeast lines and some sub faults and fractures exist along Zagros. In Figure 8, the location of stations and blind faults are depicted on a geological map and satellite images. 
Figure 8: Location of identified blind faults on maps

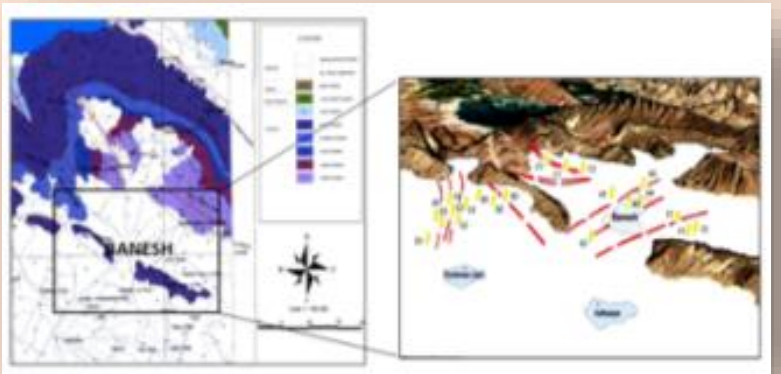

\section{REFERENCES}

Ako, B.D. and Olorunfemi, M.O. Geoelectric survey for Groundwater in the Newer Basalts of VomPlateau Stat. Nig. J. Min. Geol. 25. 247-450, 1989.

Aqanabaty, A. Geology of Iran. Geological Survey of Iran, 2004.

Berberian, M. Historical hazards in Iran prior to 1900 , International Institute of Earthquake Engineering and Seismology, 603, 1994.

Berberian, M. Contribution to the Seismotectonics of Iran (Part II), G. S. I., Rep. No. 39, pp. 143-186, 1976.

Crellier, S., Reddy, K.R, Gangathulasi, J., Adib, R., and Peters, C. Correlation between electrical resistivity and moisture content municipal solid waste in bioreactore landfill: Geotechnical special publication. N. 163, ASCE press, Reston, Virginia., 2007. https:// doi.org/10.1061/40907(226)11

Hessami, K., Koyi, H. A. \& Talbot, C. J. The significance of strike-slip faulting in the basement of the Zagros fold and thrust belt. Journal of Petroleum Geology, 24, 5-28, 2001. https://doi.org/10.1111/i.1747-5457. 2001.tb00659.x

Kalagari, A. A. Principles of Geophysical Exploration. Tabriz University, 2010.

Knisel, C. Assesment of subsurface lithology in mountain environments using 2D resistivity imaging. Geomorphology, 80,33-44, 2006. https://doi.org/10.1016/j.geomorph. 2005.09.012

Milson, J. Field Geophysics, Geological Society of London Handbook Series, pp. 9091, 1989.

Shahsavari, A. Morphotechtonic Analysis of Beyza Plain, MA Thesis, Shiraz University, 2003.

Stocklin, J. Structural history and tectonics of Iran: a review. American Association of Petroleum Geologists Bulletin, v. 52, no. 7, p. $1229-1258,1968$. https://doi.org/10.1306/ 5D25C4A5-16C1-11D7-8645000102C1865D

Sudha, K., Israil.M., Mittal, S., Rai, J., J. Soil characterization using electrical resistivity tomography and geotechnical investigation. Journal of Applies Geophysics, 67, 74-79, 2009. https://doi.org/10.1016/i.jappgeo.20 08.09.012

Yadav, G. S. and Abolfazli, H. Geoelectrical sounding and their relationship to hydraulic parameters in semi-arid regions of Jalore. north-western India. J. Applied Geophysics. 39: 35-51, 1998. https://doi.org/10.101 6/S0926-9851(98)00003-2

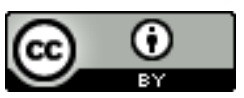
License information: This is an openaccess article distributed under the terms of the Creative Commons Attribution License, which permits unrestricted use, distribution, and reproduction in any medium, provided the original work is properly cited.

Article received on May 08, 2019.

Evaluated July 26,2019.

Accepted on August 05, 2019.

Published on August 07, 2019.

How cite this article (ABNT):

FARHANG, Raheleh; ASADI, Abdolmajid. Geophysical researches for identification of 
hidden faults in the western region of Banesh, Fars, Iran. Estação Científica (UNI-

FAP), Macapá, v. 8, n. 3, p. 61-69, Sept./

Dec. 2018. 